100

Wh. 230

y

$31-1 \mathrm{~A}-5149$

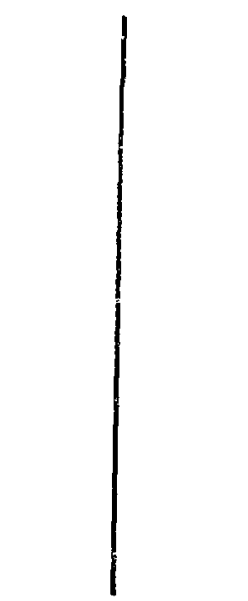

Some Factors Bearing on the Decay and Reversal of the Plasma Current in Z Pinches 
This report was prepared as an account of work sponsored by the United States Government. Neither the United States nor the United States Atomic Energy Commission, nor any of their employees, nor any of their contractors, subcontractors, or their employees, makes any warranty, express or implied, or assumes any legal liability or respensibility for the accuracy, completeness or usefuiness of any information, apparatus, product or process disclosed, or represents that its use would not infringe privately owned rights.

Printed in the United States of America. Available from National Technical Information Service

U. S. Department of Commerce

5285 Port Royal Road

Springfield, Virginia 22151

Price: Printed Copy $\$ 20 ;$ Microfiche $\$ 0.95$ 


\title{
Some Factors Bearing on the Decay and Reversal of the Plasma Current in Z Pinches
}

\author{
by
}

G. P. Boicourt

This NOTICE

This report was prepared as an account of work United States nor the States Government. Neither Comic Enerry Comployes, nor any of Tholf contractors, subcontractors, or their employees, mekes any warranty, oxpress or implled, or assumes any legal liability or responabulty for the accuracy, completeness or usefulnew of any information, apparatus, product or procese disclosed, or represents that its use would not infringe grivately owned rights. 
SOME FACTORS BEARING ON THE DECAY AND REVERSAL

OF THE PLASMA CURRENT IN 2 PINCHES

by

G. P. Bolcourt

ABSTRACT

The decay and reversal of currents in 2 -pinch equivalent circuits are examined. It 1s shows that the physically observed effects do not require special plasma properties for their explanation because they are the normal behavior of the electrical circuit.

Oomans and Meddens ${ }^{1}$ examlned the behavior of the plasma current in $Z$ pinches as a function of the external circuit and reported the possibility of generating a short-term rising plasma current after the crowbar switch is closed if a parallel circuit is added to the usual circuit. This shortterm plasma-current rise is called a pseudopower crowbar. This report provides an explanation of this phenomenon and explains the current reversal observed In the $Z$ pluch in terms of the plasma inductance and resistance.

When we close the Berles bwitch $S_{1}$ In F18. 1 , the current divides between the two parallel legs according to their impedance. Because this is an oscillating circult, this Impedance is primarily Inductive reactance; therefore, the circult with the smaller Inductance will carry the larger current. However, af ter the crowbar switch $S_{2}$ is

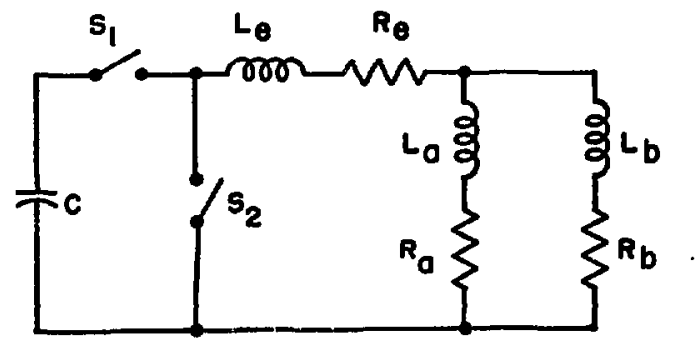

F1g. 1. Simplified 2-pinch circuit. closcd, the current w11l redistribute itself. In fact, it will rpproach the current division determined by the realstance of the legs as the circuit approaches a direct current state. If the resistance $R_{a}$ is less than $R_{b}$ and $L_{z}$ is greater than $L_{b}$, the result will be a rising current in $L_{a}$. This effect is apparent In F1g. 2 of Comans and Meddens' report, although apparently not noticed by them. In their figure it 18 the current in the primary that rises after the crowbar switch is closed. We have recalculated their case for the circult shown In Fig. 1 using their values along with a small value of $R_{m}$. To conform to their notation we have reldentified the clrcult components as follows: $L_{a}=L_{m}, R_{a}=R_{m}, L_{b}=L_{z p}$, and $R_{b}=R_{z p}$. The result of our recalculation is plotted in Fig. 2.

The calculation was done using the Net-2 circuit analysis cade. The time of crowbar switch closing was $12 \mu$ sec. Here the rise in the current in $L_{m}$ after crowbar switch closing is noticeable.

Frow the discussion above, the reason for the pseudopower crowbar phenomenon is apparent. The significance of Oomans and Meddens' work is that it shows how to obtain this phenomenon in the plasma leg by adding a third leg in parallel with the primary of the transformer. When this third leg is connected in parallel with $L_{g}$ and $L_{b}$, Its Inductance is sufficiently low with respect to $L_{b}$, and Its resistance 18 greater than $R_{b}$, a rise in current 


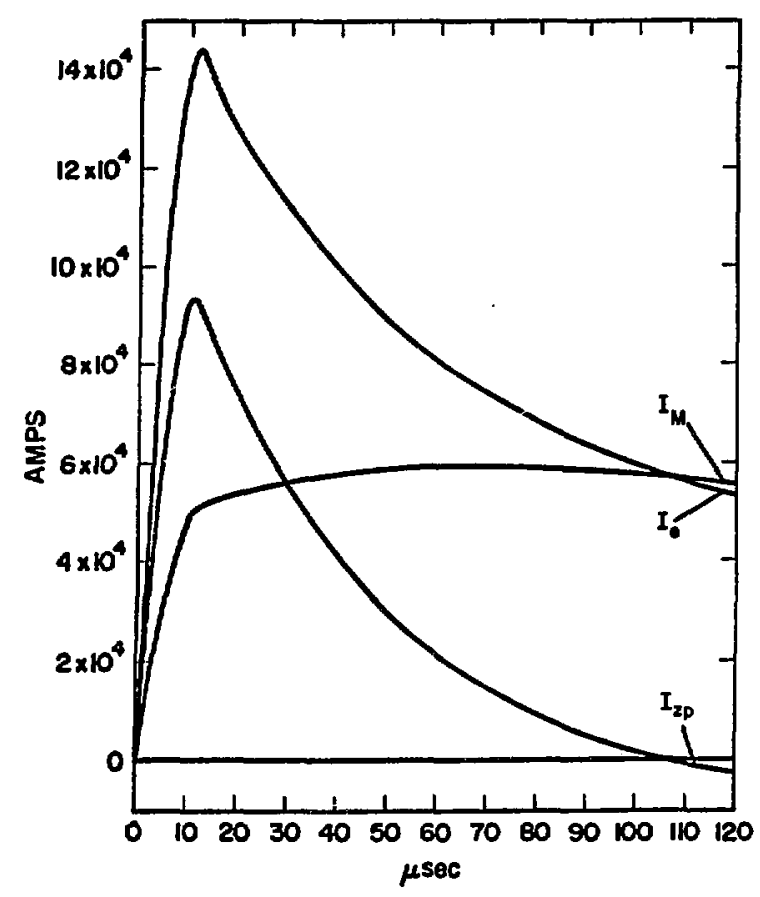

Fig. 2. Net-2 calcuiation of currents in the circuit of $\mathrm{FIB}$. 1. $C=120 \mu \mathrm{F}, \mathrm{L}_{\mathrm{e}}=300 \mathrm{nH}$,

$R_{e}=2.7 \mathrm{mbs} L_{a}=L_{m}=630 \mathrm{nH}, R_{a}=R_{m}$

$=10^{-7} \mathrm{R}, I_{b}=L_{z p}=265 \mathrm{nH}, R_{b}=g_{z p}=10 \mathrm{m \Omega}$.

in $L_{a}$ is to be expected provided $L_{a}$ is large enough that the current through it cannot change as rapidly as the plasma current.

The reversal of the current in a 2 pinch is also related to the circuit values but not necessarlly to the plasma properties. To show this we have considered the circuit of Fig. 3. This is the

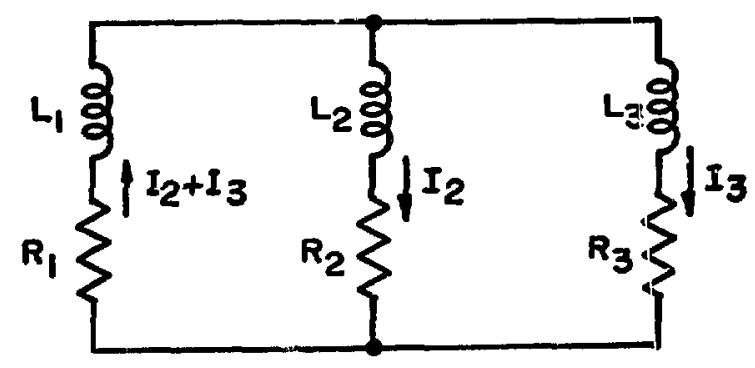

Fig. 3. Equivalent circult for 2 pinch after crowbar time. part of the circuit of $\mathrm{Fig}_{\mathrm{g}}$. 1 that needs to be examined after tine switch $\mathrm{S} 2$ is closed. We assume current $I_{02}$ and $I_{03}$ flowing at $t=0$ in the directions shown. If this system is solved, we find that the currents $I_{2}$ and $I_{3}$ are given by the following equations.

$$
\begin{aligned}
& I_{2}=\left\{\frac{\gamma I_{03}}{M_{2}-M_{1}}+\frac{\left(M_{2}+\delta\right)}{M_{2}-M_{1}} I_{02}\right\} e^{M_{1} t} \\
& -\left\{\frac{M_{1}+\delta}{M_{2}-M_{1}} I_{02}+\frac{\gamma}{M_{2}-M_{1}} I_{03}\right\} e^{M_{2} t} \\
& \text { and } \left.\quad I_{3}=\frac{1}{\gamma\left(M_{2}-M_{1}\right)}\right\}-\left[\left(M_{1}+\delta\right) \gamma I_{03}\right. \\
& \left.+\left(M_{1}+\delta\right)\left(M_{2}+\delta\right) I_{02}\right] e^{M_{1} t} \\
& +\left[\left(M_{2}+\delta\right) Y_{03}\right. \\
& \left.+\left(M_{1}+\delta\right)\left(M_{2}+\delta\right) I_{02}\right] e^{M_{2} t}
\end{aligned}
$$

$$
\text { where } \begin{aligned}
\gamma & =\left(R_{1} L_{3}-R_{3} L_{1}\right) /\left(L_{1} L_{2}+L_{1} L_{3}+L_{2} L_{3}\right) \\
\delta & =\left(R_{2} L_{3}+R_{1} L_{3}+R_{2} L_{1}\right) /\left(L_{1} L_{2}+L_{1} L_{3}+L_{2} L_{3}\right), \\
\text { and } M_{1} & =-\frac{(\alpha+\delta)}{2}+\frac{1}{2} \sqrt{(\alpha+\delta)^{2}+4(\gamma R-\alpha \delta)} \\
M_{2} & =-\frac{(\alpha+\delta)}{2}-\frac{1}{2} \sqrt{(\alpha+\delta)^{2}+4(\gamma \beta-\alpha \delta)}, \\
\text { where } \alpha & =\left(R_{1} L_{2}+R_{3} L_{1}+R_{3} L_{2}\right) /\left(L_{1} L_{2}+L_{1} L_{3}+L_{2} L_{3}\right) \\
B & =\left(R_{1} L_{2}-R_{2} L_{1}\right) /\left(L_{1} L_{2}+L_{1} L_{3}+L_{2} L_{3}\right)
\end{aligned}
$$

In the above we have assumed that $M_{1} \neq M_{2}$.

From this we can determine how long it will be af ter closure of the crowbar switch until the current $I_{3}$ passes through zero. This time is given by

$$
\begin{aligned}
& t={\frac{1}{\sqrt{(a+\delta)^{2}+4(\gamma \beta-\alpha \delta)}}}^{\log } \\
& \left.\left\{\begin{array}{ll}
\left(M_{2}+\delta\right) & \left(r I_{03}+\left(M_{1}+\delta\right) I_{02}\right.
\end{array}\right)\right\} \text {. }
\end{aligned}
$$

For example, if we use the values given for Fig. 2 w1th $I_{03}$ and $I_{02}$ taken from the Net-2 salculation, 
we find that $t$ equals $96.14 \mu s e c$ after crowbar time or 108.14 Hsec after closing the start switch. The Net-2 calculations graphed in Fig. 2 give the time

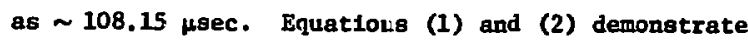
that the $\mathrm{Z}$-pinch current reversal is purely a matter of the circult parameters and has nothing to do with the plasma properties other than In how these properties affect the Inductance and resistance of the plasma.

\section{ACKNOKLEDGMENT}

I would like to thank J. A. Phillipg for bringing this subject to my attention and for his help in the analysis.

\section{REFERENCE}

1. A. A. M. Oomens and B. J. H. Meddens, "The Influence of the External Circuit on the Decay of the Induced Plasma Current," In Proce. of Second Toptcal Conf. on Pulsod High-Beta Plagmas, W. Latz, Ed., Munchen, Germany, July 3-6, 1972, Pp, 201-204. 